\title{
The relative burden of community-acquired pneumonia hospitalizations in older adults: a retrospective observational study in the United States
}

\author{
Joshua D. Brown ${ }^{1 *} \mathbb{D}$, James Harnett ${ }^{2}$, Richard Chambers ${ }^{3}$ and Reiko Sato ${ }^{4}$
}

\begin{abstract}
Background: The risk of community-acquired pneumonia (CAP) increases with age and significantly impacts morbidity and mortality in the elderly population. The burden of illness and cost of preventing CAP has not been compared to other serious diseases.

Methods: This retrospective analysis used claims data from 2014 to 2015 and compared hospitalizations for CAP, myocardial infarction (MI), stroke, and osteoporotic fractures (OF) in adults aged $\geq 65$ years enrolled in a Medicare Advantage insurance plan. Individuals who had not already been hospitalized for one of these conditions and did not have evidence of long-term care were included in the study. Hospitalizations for each condition were described by length of stay, readmissions, mortality, and total costs. Preventive measures included vaccinations for CAP and medications for MI, stroke, and OF.

Results: A total of 1,949,352 individuals were included in the cohort. In 2015, the rate of CAP-related hospitalizations was the highest at 846.7 per 100,000 person-years compared to 405 for Ml, 278.9 for stroke, and 343.9 for OF. Vaccination costs for CAP were $\$ 40.2$ million including $\$ 14.1$ million for pneumococcal and $\$ 26.1$ million for influenza vaccines. The cost of preventive medications for $\mathrm{Ml}$ and stroke reached over $\$ 661$ million and OF totaled $\$ 169$ million.

Conclusions: Although CAP has a higher burden of hospitalization and total costs than MI, stroke, and OF in the elderly population, prevention efforts were disproportionately smaller for CAP. Prioritization of CAP prevention is needed to substantially reduce the burden of CAP.
\end{abstract}

Keywords: Community-acquired pneumonia, Burden of illness, Geriatrics, Vaccinations

\section{Background}

An estimated 1.3 million annual cases of communityacquired pneumonia (CAP) occur among adults aged 65 years and older, contributing significant morbidity, mortality and economic burden in the United States [1]. Nearly $40 \%$ of CAP episodes in seniors will result in a hospitalization with an average length of stay of 5.6 days [2], incurring medical costs in excess of $\$ 18,000$ per inpatient episode $[1,3]$. The aggregate

\footnotetext{
* Correspondence: joshua.brown@ufl.edu

${ }^{1}$ Department of Pharmaceutical Outcomes \& Policy, University of Florida College of Pharmacy, Gainesville, USA

Full list of author information is available at the end of the article
}

economic burden of CAP in the Medicare fee-forservice population alone is estimated to be over $\$ 13$ billion annually and is expected to grow with the aging population $[1,4]$.

CAP includes infections not associated with encounters in the healthcare system (i.e., nosocomial or iatrogenic infections) for community-dwelling individuals. CAP risk increases with age from 18.2 cases per 1000 person-years among those aged 65-69 years up to 52.3 cases per 1000 person-years among those 85 years and older [3]. Additional risk factors include chronic obstructive pulmonary disease (COPD), asthma, diabetes, congestive heart failure (CHF),

(c) The Author(s). 2018 Open Access This article is distributed under the terms of the Creative Commons Attribution 4.0 International License (http://creativecommons.org/licenses/by/4.0/), which permits unrestricted use, distribution, and reproduction in any medium, provided you give appropriate credit to the original author(s) and the source, provide a link to the Creative Commons license, and indicate if changes were made. The Creative Commons Public Domain Dedication waiver (http://creativecommons.org/publicdomain/zero/1.0/) applies to the data made available in this article, unless otherwise stated. 
immunosuppression, cancer, and smoking [4-6]. These risk factors tend to be highly prevalent in the older population and increase the risk of more severe disease and death due to CAP $[1,3,7]$.

Other serious medical events that frequently occur in seniors are myocardial infarction (MI), stroke, and osteoporotic fractures (OF). According to the 2010 National Hospital Discharge Survey, there were an estimated 354,000 MI hospitalizations, 663,000 stroke hospitalizations, and 586,000 facture related hospitalizations in adults aged $\geq 65$ years [8]. These conditions are considered common targets for primary prevention by healthcare providers and managed care organizations because of the high prevalence of disease, modifiable risk factors, availability of proven therapies and strategies to reduce the risk of the medical event, potential for high disability, and substantial economic burden [9, 10]. In comparison, there were $621,000 \mathrm{CAP}$ hospitalizations in the same age group, which is similar or greater than that of MI, stroke, and OF.

In health systems with constrained resources, resource utilization for preventive efforts would ideally be proportional to the disease burden in the population. Prior studies have estimated the burden of illness for CAP [1, 3], but the incidence and cost of hospitalizations due to CAP have not been compared in the context of other serious diseases and how the relative burden of disease compares to the expenditures to prevent those diseases. This study sought to compare the relative burden of hospitalizations for CAP compared to MI, stroke, and OF, as well as to assess the relative expenditures of preventive measures for each disease in a population of older adults in a large, national, Medicare Advantage plan.

\section{Methods}

\section{Data source}

This retrospective cohort study utilized administrative healthcare claims data from Optum's Clinformatics ${ }^{\mathrm{Tm}}$ Data Mart (CDM) between 2014 and 2015 in a study population comprised of Medicare Advantage with Prescription Drug Plan (MAPD) beneficiaries from a large national managed care company affiliated with Optum. MAPD plans are alternative plans to "traditional" Medicare insurance coverage, often call "Part C," where federal payments are provided to private insurance companies. These organizations provide an insurance benefit which includes inpatient, outpatient, prescription coverage, and often additional dental, vision, or other benefits usually within Health Maintenance Organization (HMO) or Preferred Provider Organization (PPO) structures. Enrollment into MAPD is optional and roughly one-third of
Medicare beneficiaries enroll in MAPD coverage [11]. Compared to traditional Medicare enrollees, MAPD members tend to be older, more racially diverse, and have lower socioeconomic status [12].

The Optum Clinformatics ${ }^{\text {TII }}$ Data Mart is statistically de-identified under the Expert Determination method consistent with HIPAA and managed according to Optum customer data use agreements. These administrative claims submitted for payment by providers and pharmacies are verified, adjudicated, adjusted, and de-identified prior to inclusion. The population is geographically diverse, spanning all 50 states in the U.S.. In addition to medical claims and pharmacy claims, the data include tables with member eligibility and demographic information. The data also include standard pricing for all medical claims, pharmacy claims, and inpatient confinements. The data use an encrypted member identification number to longitudinally track members across years. Information on the month and year of death are appended to the database by Optum prior to de-identification using the Social Security Administration Death Master File.

\section{Study population}

Adults aged 65 to 89 years with continuous MAPD enrollment from January 1, 2014 through December 31, 2015 were included in this study. Censoring due to death in 2015 was permitted since it was an outcome of interest. Hospitalization for CAP, MI, stroke, and OF were identified during the 2015 calendar year. The 2014 calendar year was used to assess cohort clinical characteristics as well as to capture preventive measures for each of the four conditions. Subjects who had a hospitalization for CAP, MI, stroke or OF or a cumulative stay in a skilled nursing facility for $\geq 90$ days during 2014 were excluded to create a cohort that was communitydwelling and free of the hospitalizations of interest at the start of follow-up in 2015.

\section{Cohort characteristics}

Age, gender, region, and low income subsidy status were assessed as of January 1, 2015 from the enrollment data. Individuals were categorized into age groups: 65-69, $70-74,75-79,80-84$, and $85-89$ years; geographic region was based on Census regions (North Central, Northeast, South, West, Unknown). Key comorbidities were identified using ICD-9 and corresponding ICD-10 codes. Deyo-Charlson comorbidities were calculated as a weighted summary score for each individual [13, 14]. Coding algorithms of the comorbidity classifications are summarized in Appendix 1 Table 4. 


\section{Hospitalization metrics}

CAP, MI, stroke, and OF hospitalizations were identified beginning on January 1, 2015 in the medical claims using diagnosis codes listed in Appendix 1 Table 4. Only hospital admissions with a primary diagnosis of one of these four conditions were included. Hospitalizations for CAP were identified based on prior work [1], with slight modification to use a primary diagnosis for pneumonia or a primary diagnosis of septicemia or respiratory failure with a diagnosis of pneumonia during the same hospital visit. To distinguish CAP from potential hospitalacquired pneumonia, index CAP hospitalizations with claims indicating other hospitalization, skilled nursing facility, or hospice care in the 14 days preceding a pneumonia hospitalization were excluded.

A 30-day post-discharge period was used to assess hospital readmission for any condition, similar to "all cause readmission" metrics already in use as measures of care quality after a hospitalization [15]. After a 30-day period had elapsed with no readmissions, new hospitalizations for any study condition were counted. All-cause deaths after the index hospitalization were also recorded. However, due to data privacy requirements, dates were restricted at the month level. Thus, we recorded deaths that occurred in the same month or the following month of index admissions of interest.

Each hospitalization and readmission included the length of stay (LOS) and the sum of the amounts paid by the individual and the health plan. Total episode costs included the costs of the index hospitalization and any readmissions observed during the 30-day window. Costs for preventive measures were summarized as costs to the health insurer, member out-of-pocket (OOP) cost, total costs (health insurer plus member OOP), and summarized as per member per year (PMPY) expenditures based on the total population.

\section{Preventive medication/vaccinations}

Preventive measures for CAP included influenza and pneumococcal vaccinations, consistent with Infectious Diseases Society of America and the American Thoracic Society Consensus Guidelines on the Management of Community-Acquired Pneumonia [16]. Preventive medications for MI and stroke comprised of antihypertensives, statins, aspirin, anticoagulants, and antiplatelet medications. OF preventive measures included bisphosphonates, selective estrogen receptor modulators, and injectable therapies (denosumab and teriparatide). All medications were identified by MediSpan Generic Product Identifier (GPI) codes in the pharmacy claims. Injectable medications and vaccinations were also identified by Current Procedural Terminology codes and Healthcare Common Procedure Coding System codes in the medical claims. Codes for preventive medications are available in Appendix 2 Table 5.

Total summed costs for hospitalizations, readmissions, and total combined costs were described as well as per event costs. Admission, re-admission, and mortality rates were standardized to events per 100,000 life-years to allow direct comparison between conditions within the cohort. Data management and analysis were conducted using SAS Enterprise Guide 5.1 (SAS Institute, Cary, NC). This manuscript was drafted in accordance with STROBE reporting guidelines (http://www.strobe-statement.org/) for observational studies.

\section{Results}

After applying sample selection requirements, $1,949,352$ subjects were included in the final study cohort (Appendix 3 Table 6), contributing 1,940,589 person-years after correction for those who died during follow-up in 2015. Baseline demographic and clinical characteristics of the cohort are provided in Table 1 . The mean age was 75.9 years, $57.8 \%$ of the cohort was female, and the cohort was geographically diverse across regions. The average DeyoCharlson comorbidity index score was 1.3. Diabetes (25.0\%), chronic pulmonary disease (14.7\%), coronary artery disease (14.2\%), and renal disease (11.3\%) were the most prevalent comorbid conditions among those selected for evaluation.

There were 15,701 older adults who experienced a CAP hospitalization, with a total of 16,430 CAP hospitalizations during 2015 - a rate of 846.7 hospitalizations per 100,000 person-years (Table 2). Comparatively, there were 7859 hospitalizations for MI (405 per 100,000 person-years), 5412 hospitalizations for stroke (278.9 per 100,000 person-years), and 6674 hospitalizations for OF (343.9 per 100,000 person-years). The mean [SD] LOS for CAP hospitalizations was 5.2 [6.2] days and statistically longer than MI (4.5 [6.3] days, $p<0.001)$, stroke (4.1 [5.6] days, $\mathrm{p}<0.001)$, and OF (4.2 [3.4] days, $p=0.002)$. The 30 -day readmission rate percent was $10.0 \%$ for CAP, $10.5 \%$ for MI, $7.7 \%$ for stroke, and $7.9 \%$ for OF. The mortality rate per 100,000 persons for CAP was significantly higher than all comparison diseases: 22.5 for CAP versus 5.3 for MI, 9.7 for stroke, and 5.8 for OF.

The cost per index hospitalization was $\$ 13,825$ for CAP, which was lower than all other conditions 
Table 1 Cohort demographic and clinical characteristics $(N=1,949,352)$

\begin{tabular}{lll}
\hline & Variable Description & $\mathrm{N}(\%)$ \\
\hline Age & & \\
& $65-69$ & $402,909(20.7 \%)$ \\
& $70-74$ & $566,324(29.1 \%)$ \\
& $75-79$ & $397,143(20.4 \%)$ \\
& $80-84$ & $288,020(14.8 \%)$ \\
& $85-89$ & $294,956(15.1 \%)$ \\
Gender & & \\
& Female & $1,126,172$ \\
& & $(57.8 \%)$ \\
& Male & $823,180(42.2 \%)$
\end{tabular}

Geographic region

North Central
Northeast
South
West
Unknown

Low Income Subsidy

Yes
No
Unknown

Deyo-Charlson comorbidity index score

$$
\text { Mean (SD) }
$$

Comorbidities

Myocardial infarction
Peripheral vascular disease
Cerebrovascular disease
Dementia
Rheumatologic disease
Peptic ulcer disease
Hemiplegia or paraplegia
Renal disease
Chronic pulmonary disease
Asthma
Heart Failure
Cardiomyopathy
Diabetes
Diabetes with chronic
complications
Liver Disease
Alcoholism
Coronary artery disease

Immunocompromising conditions, N(\%)

$$
\text { Asplenia }
$$

$382,856(19.6 \%)$

$286,616(14.7 \%)$

643,917 (33.0\%)

3486 (0.2\%)

$258,476(13.3 \%)$

$1,577,011$

(80.9\%)

$113,865(5.8 \%)$

$1.3(1.9)$

$55,652(2.9 \%)$

124,624 (6.4\%)

175,251 (9.0\%)

$31,640(1.6 \%)$

49,924 (2.6\%)

17,117 (0.9\%)

6503 (0.3\%)

$219,910(11.3 \%)$

285,668 (14.7\%)

38,117 (2.0\%)

$120,061(6.2 \%)$

$44,327(2.3 \%)$

486,478 (25.0\%)

150,350 (7.7\%)

55,746 (2.9\%)

11,983 (0.6\%)

$277,519(14.2 \%)$

$170(<0.1 \%)$
632,477 (32.5\%)
Table 1 Cohort demographic and clinical characteristics ( $N=1,949,352)$ (Continued)

\begin{tabular}{lll}
\hline & Variable Description & $N(\%)$ \\
\hline & Sickle cell disease & $192(<0.1 \%)$ \\
& HIV/AIDS & $1951(0.1 \%)$ \\
& Cancer & $131,009(6.7 \%)$ \\
& Leukemia, leukemia & $20,473(1.1 \%)$ \\
& or myeloma & \\
& $\begin{array}{l}\text { Advanced stage } \\
\text { renal disease }\end{array}$ & $4908(0.3 \%)$ \\
& $\begin{array}{l}\text { Immunosuppressive } \\
\text { medication use }\end{array}$ & $58,127(3.0 \%)$ \\
$\begin{array}{l}\text { Death in 2015 } \\
\text { Total person years } \\
\text { of follow-up }\end{array}$ & & $16,125(0.8 \%)$ \\
\hline
\end{tabular}

Abbreviations; SD: standard deviation

(Table 2). Because of the much higher incidence of CAP hospitalization compared to MI, OF, and stroke, the total cost of index CAP hospitalizations was much higher at \$227.1 million compared to \$205.2 million for MI, $\$ 81.9$ million for stroke, and $\$ 127.8$ million for OF. Similarly, total readmission costs associated with CAP were the highest at $\$ 23.3$ million, compared to $\$ 11.6$ million, $\$ 5.4$ million, and $\$ 7.7$ million for MI, stroke, and OF, respectively. Costs per readmission were similar between the conditions. The total costs, which include the sum of the index hospitalization costs and any associated readmission, totaled over \$250.4 million for CAP compared to $\$ 216.8$ million for MI, $\$ 87.3$ million for stroke, and $\$ 135.6$ million for OF (fig. 1).

During 2014, 7.6\% of individuals received at least one pneumococcal vaccination and $45.31 \%$ received an influenza vaccination (Table 3). Health plan expenditures on pneumococcal and influenza vaccinations totaled \$14.1 million (\$7.3 PMPY) and \$26.1 million ( $\$ 13.4$ PMPY), respectively. Member OOP costs made up $<1 \%$ of total expenditures as health insurance coverage typically includes the entire cost of preventive vaccinations. Preventive medications for MI and stroke were used by about $60 \%$ of the cohort in 2014 (Table 3). Combined costs of MI and/or stroke preventive medications exceeded \$661 million (\$339.33 PMPY). Prevention for OF was used by $6.3 \%$ of the cohort with total costs of $\$ 169$ million (\$86.74 PMPY).

\section{Discussion}

MI, stroke, and OF are important disease states that contribute significant morbidity and mortality in individuals over 65 years of age. As such, they are a 
Table 2 Comparison of CAP, MI, stroke, and OF related hospitalizations in 2015

\begin{tabular}{|c|c|c|c|c|}
\hline Characteristic & CAP & $\mathrm{Ml}$ & Stroke & OF \\
\hline Persons hospitalized & 15,701 & 7683 & 5317 & 6614 \\
\hline Number of hospitalizations & 16,430 & 7859 & 5412 & 6674 \\
\hline Incidence of hospitalization rate per 100,000 person-years & 846.7 & 405.0 & 278.9 & 343.9 \\
\hline Number of readmissions & 1874 & 950 & 458 & 574 \\
\hline 30-day readmission rate (\%) & 10.0 & 10.5 & 7.7 & 7.9 \\
\hline Number of deaths within 30 days of discharge & 439 & 104 & 189 & 112 \\
\hline Mortality rate during same or following month per 100,000 persons & 22.5 & 5.3 & 9.7 & 5.8 \\
\hline \multicolumn{5}{|l|}{ Length of stay per hospitalization } \\
\hline Mean (SD) & $5.2(6.2)$ & $4.5(6.3)$ & $4.1(5.6)$ & $4.2(3.4)$ \\
\hline Median & 4 & 3 & 3 & 4 \\
\hline \multicolumn{5}{|l|}{ Length of stay per readmission } \\
\hline Mean (SD) & $4.9(4.3)$ & $4.2(4.1)$ & $4.2(4.5)$ & $4.7(4.1)$ \\
\hline Median & 4 & 3 & 3 & 4 \\
\hline \multicolumn{5}{|l|}{ Cost per hospitalization } \\
\hline Mean (SD) & $13,825(17,341)$ & $26,114(28,118)$ & $15,138(15,810)$ & $19,156(14,845)$ \\
\hline \multicolumn{5}{|l|}{ Cost per readmission } \\
\hline Mean (SD) & $12,422(13,260)$ & $12,177(14,925)$ & $11,681(11,525)$ & $13,446(13,301)$ \\
\hline \multicolumn{5}{|l|}{ Cost per episode } \\
\hline Mean (SD) & $15,241(19,078)$ & $27,586(29,423)$ & $16,126(17,225)$ & $20,312(16,384)$ \\
\hline Sum of hospitalization costs (\$) & $227,145,454$ & $205,230,868$ & $81,926,896$ & $127,847,139$ \\
\hline Sum of readmission costs (\$) & $23,280,008$ & $11,568,507$ & $5,350,202$ & $7,718,322$ \\
\hline Total costs (\$) & $250,425,463$ & $216,799,375$ & $87,277,098$ & $135,565,461$ \\
\hline
\end{tabular}

List of abbreviations: CAP: community-acquired pneumonia; MI: myocardial infarction; OF: osteoporotic fracture; SD: standard deviation
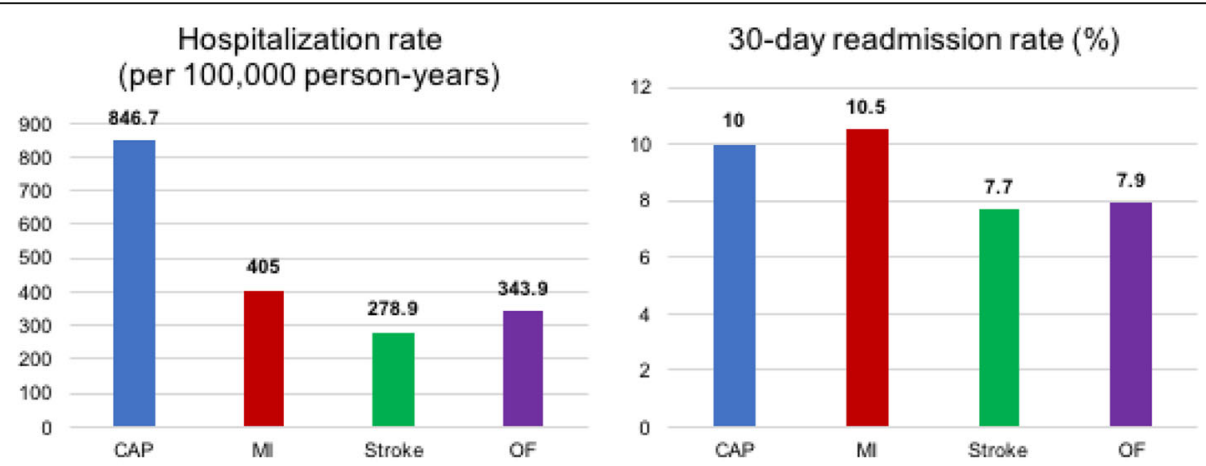

Total costs (millions \$)

Death rate (per 100,000 persons)
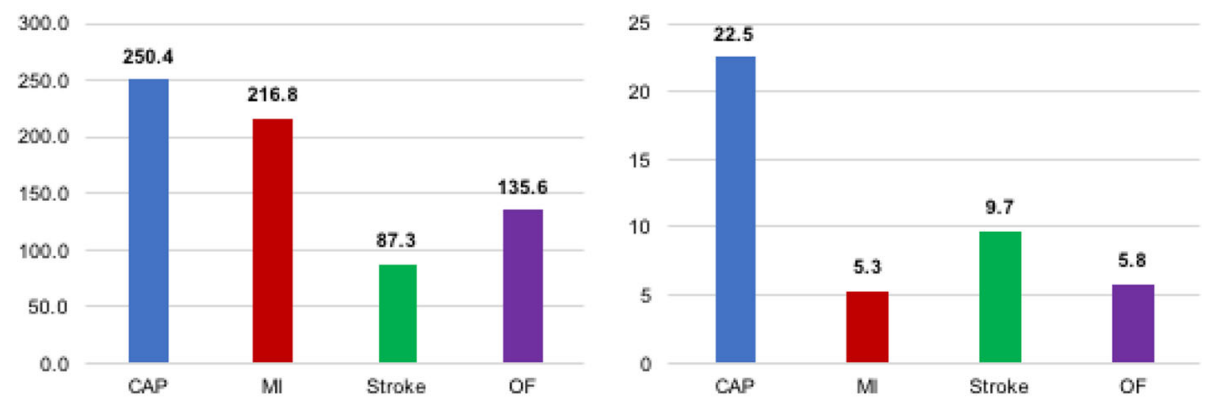

Fig. 1 Comparison of hospitalization metrics for CAP, MI, stroke, and OF 
Table 3 Preventive medication and vaccination use in 2014

\begin{tabular}{|c|c|c|c|c|c|}
\hline Preventive measure & Individuals treated N (\%) & Total health plan cost & Patient OOP & Total cost & PMPYa $^{a}$ \\
\hline Pneumococcal vaccination & $147,552(7.6 \%)$ & $\$ 14,142,934$ & $\$ 6930$ & $\$ 14,149,780$ & $\$ 7.26$ \\
\hline Influenza vaccination & $883,319(45.3 \%)$ & $\$ 26,115,315$ & $\$ 14,643$ & $\$ 26,129,745$ & $\$ 13.40$ \\
\hline Total & $922,414(47.3 \%)$ & $\$ 40,255,322$ & $\$ 21,573$ & $\$ 40,276,597$ & $\$ 20.66$ \\
\hline \multicolumn{6}{|l|}{ MI/Stroke Prevention } \\
\hline Antihypertensives & $1,103,865(56.6 \%)$ & $\$ 259,953,965$ & $\$ 120,376,142$ & $\$ 369,173,588$ & $\$ 189.38$ \\
\hline Statins & $754,659(38.7 \%)$ & $\$ 146,574,868$ & $\$ 48,844,928$ & $\$ 194,778,686$ & $\$ 99.92$ \\
\hline Aspirin & $2514(0.1 \%)$ & $\$ 11,569.57$ & 8.40 & $11,573.70$ & 0.01 \\
\hline Antiplatelets & $108,899(5.6 \%)$ & $\$ 49,170,046$ & $\$ 13,925,749$ & $\$ 63,053,238$ & $\$ 32.35$ \\
\hline Anticoagulants & $109,114(5.6 \%)$ & $\$ 25,344,062$ & $\$ 9,197,641$ & $\$ 34,451,541$ & $\$ 17.67$ \\
\hline Total MI/Stroke & $1,225,741(62.9 \%)$ & $\$ 481,054,511$ & $\$ 192,344,468$ & $\$ 661,468,627$ & $\$ 339.33$ \\
\hline Bisphosphonates & $98,129(5.0 \%)$ & $\$ 26,495,337$ & $\$ 8,544,260$ & $\$ 34,128,920$ & $\$ 17.51$ \\
\hline SERMs & $11,437(0.6 \%)$ & $\$ 12,752,847$ & $\$ 3,739,518$ & $\$ 16,482,842$ & $\$ 8.46$ \\
\hline Denosumab & $13,567(0.7 \%)$ & $\$ 103,203,578$ & $\$ 3,602,221$ & $\$ 106,801,838$ & $\$ 54.79$ \\
\hline Teriparatide & $1261(0.1 \%)$ & $\$ 10,494,134$ & $\$ 1,186,876$ & $\$ 11,680,624$ & $\$ 5.99$ \\
\hline Total & $121,870(6.3 \%)$ & $\$ 152,945,896$ & $\$ 17,072,875$ & $\$ 169,094,223$ & $\$ 86.74$ \\
\hline
\end{tabular}

${ }^{\mathrm{a}}$ Based on the Total Cost divided by the total population size

Abbreviations: CAP: community-acquired pneumonia; MI: myocardial infarction; OF: osteoporotic fracture; ACEi: angiotensin converting enzyme inhibitors; ARBs: angiotensin receptor blockers; SERMs: selective estrogen receptor modulators; PMPY: per person per year; OOP: out-of-pocket

large focus of primary care providers and managed care organizations since there are effective preventive medications available. In this cohort representative of a MAPD insured population, the insurer spent over $\$ 661$ million on medications for primary prevention of $\mathrm{MI}$ and stroke and an additional \$169 million on primary prevention agents for OF. In contrast, only $\$ 14.1$ million dollars were spent on pneumococcal vaccinations and \$26.1 million on annual influenza vaccination - both effective preventive interventions for CAP [16].

In order to prevent CAP, the Infectious Diseases Society of America and the American Thoracic Society guidelines recommend smoking cessation, influenza vaccination, and pneumococcal vaccinations for adults aged $\geq 65$ years and for those 19-64 years with chronic medical conditions [16]. Likewise, the current Advisory Committee on Immunization Practices guidelines recommend vaccination for adults aged $\geq 65$ years with both PCV13 and PPSV23 vaccines in sequence [17]. Immunization will protect against influenza virus and vaccine serotypes of Streptococcus pneumoniae (Pneumococcus), which are among the most common causes and co-pathogens associated with pneumonia [17-21]. Pneumococcal vaccination decreases the rate of hospitalization associated with CAP and also lowers the risk of invasive disease such as pneumococcal meningitis and bacteremia [20-22]. Influenza vaccination has also been reported to reduce the risk of influenza-associated hospitalization for CAP [23].
The proportion of individuals receiving pneumococcal vaccination was $7.57 \%$ during 2015 in the cohort. Given that pneumococcal vaccination is generally once per lifetime in the elderly population, this can be considered a "yearly uptake" of vaccination in the population whereas the lifetime uptake is estimated to be nearly $60 \%[24,25]$. Similarly, less than $50 \%$ of the cohort received an influenza vaccination. This vaccination use falls short of the Healthy People 2020 goal of $90 \%$ pneumococcal and influenza vaccination in the older population [26]. Further, the uptake of the recommended two pneumococcal vaccine sequence was estimated to be only $18.3 \%$ in adults aged $\geq 65$ years since the most recent guideline update highlighting that there are ample opportunities to improve adult pneumococcal vaccination rates [27].

Pneumococcal and influenza vaccination in adults over the age of 65 has been identified as a highpriority prevention service and vaccinations are recognized as ones of the most under-utilized but most effective, efficient, and cost-effective primary prevention services [28-31]. Even with $100 \%$ vaccination rate for influenza, the total costs would remain a fraction of the preventive costs for other diseases. Vaccinations are also annual or one-time interventions; thus, there are no recurring monthly costs or concerns for adherence compared to prevention for the other disease states. Several factors could contribute to low vaccination rates at the point of care 
including perceived financial and access issues, patient and physician knowledge of vaccination status or recommendations, as well as prioritization of care in the time window allotted for a wellness visit [32, 33]. Vaccinations may be prime candidates for increased intervention as it is relatively simple to implement by increasing awareness of vaccine safety, efficacy, and availability through managed care organizations or healthcare provider outreach to patient.

Access to vaccinations has increased due to provisions in the Affordable Care Act requiring zero cost-sharing [34] as well as the expanded role of community pharmacists to administer vaccinations $[35,36]$. For seniors, Medicare coverage has been updated to allow compliance with the updated guidelines with coverage for the updated two-vaccination regimen [37]. Factors associated with vaccine uptake include perceptions about vaccine safety and whether a healthcare provider makes a recommendation [38-40]. Public awareness about the safety and efficacy of vaccinations must continue to be a priority for public health [41]. In addition, quality metrics by which health plans and physicians are measured should be updated to drive quality based on the most recent vaccination guidelines [42, 43].

The utilization and costs of vaccinations protecting against CAP display a clear disparity and an opportunity to provide more effective preventive efforts, especially when compared to the overall relative burden of CAP in this population. This is magnified when compared to MI, stroke, and OF and the yearly cost of preventive efforts spent for these disease states relative to the burden observed in the population. While it is warranted to focus on these more commonly feared diseases of the elderly, our study shows a tremendous burden of CAP hospitalizations in the older population that greatly exceeds that of MI, stroke, and OF - nearly double the hospitalization rates of the other disease states. Furthermore, total costs, LOS, readmissions, and associated mortality were comparable or higher with CAP-related hospitalizations than the other diseases.

\section{Limitations}

Limitations common to studies using administrative claims data apply to this study [44-46]. These include a lack of certain information in the database (e.g. lab results, smoking status, weight, and health behavior information) and errors or omissions in claims coding. Data were from a single national MAPD health plan with a diverse population of older adults residing in broad geographic regions. Because this study uses data from a single insurer's members only, the results may not be generalized to the general population. This study limited the cohort to members who did not have one or more hospitalizations in the 2014 pre-index period to focus on primary prevention costs rather than in a population with previous disease. This underestimates the burden of all of the disease states from a health plan perspective but does not bias the comparison between the disease states. The current study underestimated the burden of CAP since only inpatient CAP episodes, which have been shown to include only $40 \%$ of cases in the older population, were considered $[1,8]$. Additionally, the study only considered primary hospital diagnosis. In cases of pneumonia, it is possible that hospitals code a different cause as the primary diagnosis if an underlying condition is exacerbated that requires serious management - thus further underestimating our estimated burden of CAP episodes. Medications or vaccinations obtained without utilizing an insurance benefit were unobserved in this study. This may include over-thecounter medications (e.g. aspirin to treat MI or stroke), cash payments for medications or vaccines, medications filled using low-cost generic programs [47], and vaccinations received through employers or other health fairs. This study also grouped together medication classes commonly used for primary prevention for $\mathrm{MI}$ and stroke. However, indications for each medication cannot necessarily be confirmed and may have been used to treat other conditions (e. g. anticoagulants prescribed for venous thromboembolism). Lastly, the data may have underestimated death as this was based on the Social Security Administration Death Master File for which some states ceased providing data in 2011. Also, discharge status of "expired" is not available given discharge date would represent the date of death which may jeopardize data de-identification.

\section{Conclusion}

In this study of seniors with Medicare Advantage insurance coverage, the rate of CAP-related hospitalization was nearly double that of MI, stroke, and OF. CAP also had higher 30-day readmission rates than stroke and $\mathrm{OF}$ and increased mortality versus MI, stroke and OF. Despite higher incidence and high overall total costs, expenditures on preventive vaccinations were a fraction of the expenditures for these other disease states. Given suboptimal vaccination rates that fall below national goals, public health officials, healthcare providers, and managed care organizations should prioritize efforts to increase flu and pneumococcal vaccinations to reduce the significant burden of CAP in the older population. 


\section{Appendix 1}

Table 4 Disease state ICD-9 Coding for outcomes and comorbidities. ICD-9 codes used throughout the study

\begin{tabular}{|c|c|}
\hline Disease State & ICD-9 Codes \\
\hline \multicolumn{2}{|l|}{ Hospitalizations } \\
\hline Community Acquired & 1) $480 . x-486 . x, 487.0$ Pneumonia as a principal diagnosis; OR \\
\hline Pneumonia (CAP) & $\begin{array}{l}\text { 2) } 518.8 \times \text { Respiratory Failure or 038.xx Septicemia as a principal diagnosis with Pneumonia as a secondary } \\
\text { diagnosis on the same claim line }\end{array}$ \\
\hline Acute Myocardial Infarction & 410.xx \\
\hline Stroke & $433 . \times 1,434 . \times 1,436 . x x$ \\
\hline \multicolumn{2}{|l|}{ Osteoporotic Fractures } \\
\hline Hip, closed & $820.0,820.2,820.8,733.14$ \\
\hline Forearm, closed & 813.0, 813.2, 813.4, 813.8, 733.12 \\
\hline Pelvis, closed & $808.0,808.2,808.4,808.8$ \\
\hline Distal femur, closed & $821.0,821.2,733.15$ \\
\hline Wrist, closed & $813.4,733.12$ \\
\hline Humerus, closed & $812.0,812.2,812.4,733.11$ \\
\hline Tibia/fibula, closed & $823.0,823.2,823.8,733.16$ \\
\hline \multirow[t]{2}{*}{ Clavicle, closed } & 810.0 \\
\hline & $\begin{array}{l}\text { (excluding E-codes for fractures due to accident or trauma (E800-E848, E881-E884, E908-E909, E916-E928) and revision surgeries } \\
\text { (ICD-9 procedure codes } 00.71,81.53,78.6 \text {; ICD-9 Diagnosis codes 733.81, 733.82) }\end{array}$ \\
\hline \multicolumn{2}{|l|}{ Comorbidities } \\
\hline Chronic Pulmonary Disease & 490.xx-496.xx, 500.xx-505.xx, 506.4 \\
\hline $\begin{array}{l}\text { Cancer (Including Leukemia } \\
\text { and Lymphoma) }\end{array}$ & 140.xx-172.xx, 174.xx-195.xx, 200.xx-208.xx \\
\hline Asthma & ICD-9 Diagnosis: 493.0x-493.2x \\
\hline Heart failure & ICD-9 Diagnosis: 428.xx \\
\hline Cardiomyopathy & ICD-9 Diagnosis: $425 . x x$ \\
\hline Diabetes & ICD-9 Diagnosis: 249.xx-250.xx, 648.xx \\
\hline Liver disease & ICD-9 Diagnosis: 570.xx-573.xx, V10.017 \\
\hline Coronary artery disease & ICD-9 Diagnosis: 414.0x \\
\hline
\end{tabular}




\section{Appendix 2}

Table 5 Preventive medication coding algorithm. Medication codes used throughout the study

\begin{tabular}{|c|c|}
\hline Medication class & GPI number (most specific level required) \\
\hline \multicolumn{2}{|l|}{ Medications to prevent pneumonia } \\
\hline Influenza vaccine & $\begin{array}{l}1,710,002,020,1,710,002,021,1,710,002,023,1,710,002,040,1,710,002,044,1,710,002,050,1,710,002,061, \\
1,710,002,064 \\
\text { HCPCS G0008 } \\
\text { CPT } 90655,90,656,90,657,90,658,90,660,90,662\end{array}$ \\
\hline Pneumococcal vaccine & $\begin{array}{l}1,720,006,500,1,720,006,510,1,720,006,530 \\
\text { HCPCS G0009, CPT 90669, 90,670, 90,732 }\end{array}$ \\
\hline \multicolumn{2}{|c|}{ Medications to prevent $\mathrm{Ml}$ and/or stroke } \\
\hline ACE Inhibitors & $3610,369,915,369,918$ \\
\hline ARBs & $3615,369,940$ \\
\hline Beta-blockers & $33,369,920$ \\
\hline Calcium channel blockers & $34,369,915$ \\
\hline Diuretics & $37,369,918,369,920,369,940,369,950,369,955,369,970,369,980,369,990$ \\
\hline \multicolumn{2}{|c|}{ Anticoagulants (warfarin and NOACs) } \\
\hline Aspirin & $64,100,010,6,410,990,203,6,410,990,204,6,410,990,202,6,410,990,210$ \\
\hline Anti-platelet agents & 8515 \\
\hline Statins & 3940 \\
\hline Other cholesterol medications & 39 \\
\hline \multicolumn{2}{|l|}{ Medications to prevent OF } \\
\hline Bisphosphonates & 300,420; HCPCS J3489 \\
\hline SERMs (raloxifene) & $3,005,306,010$ \\
\hline Denosumab & 3,004,453,000; HCPCS J0897 \\
\hline Teriparatide & 3,004,407,000; HCPCS J3110 \\
\hline
\end{tabular}

\section{Appendix 3}

Table 6 Study cohort attrition. Describes the cohort select process and total number of inclusions and exclusions

\begin{tabular}{|c|c|c|c|c|}
\hline \multirow{2}{*}{$\begin{array}{l}\text { Cohort Selection Step } \\
\text { 1. All Medicare patients enrolled in Optum DOD between Jan 1, } 2014 \text { and Dec 31, } 2015\end{array}$} & \multicolumn{2}{|c|}{$\begin{array}{l}\text { Subjects } \\
\text { remaining }(\mathrm{N}, \%)\end{array}$} & \multicolumn{2}{|c|}{$\begin{array}{l}\text { Subjects } \\
\text { excluded }(N, \%)\end{array}$} \\
\hline & $3,971,785$ & 100.000 & & \\
\hline 2. (1) and Medicare beneficiaries aged $65-89$ years as of $1 / 1 / 2015$ & $3,533,736$ & 88.971 & 438,049 & 11.029 \\
\hline 3. (2) and with continuous medical/pharmacy eligibility from 1/1/2014-12/31/2015 or death if occurs in 2015 & $1,993,580$ & 50.194 & $1,540,156$ & 38.777 \\
\hline 4. (3) and excluding members with hospitalization for CAP, MI, stroke or OF during 2014 & 1951,510 & 49.134 & 42,070 & 1.059 \\
\hline $\begin{array}{l}\text { 5. (4) and excluding members with a cumulative stay } \geq 90 \text { days in skilled nursing facility or long-term care } \\
\text { during } 2014\end{array}$ & $1,949,352$ & 49.080 & 2158 & 0.054 \\
\hline Final study sample & $1,949,352$ & & & \\
\hline
\end{tabular}




\section{Abbreviations}

CAP: Community-acquired pneumonia; LOS: Length of stay; MAPD: Medicare Advantage with Prescription Drug Plan; MI: Myocardial infarction; OF: Osteoporotic fracture

\section{Funding}

The study was funded by Pfizer, Inc.

\section{Availability of data and materials}

Data are proprietary and used under license and cannot be made publicly available. Please contact the authors for inquiries regarding the data.

\section{Authors' contributions}

$J B, J H, R C$, and RS designed study and interpreted the results. JH and RC led the data analysis. JB drafted the manuscript and JB, JH, RC, and RS all critically revised the manuscript. JB, JH, RC, and RS approved the final version of the manuscript and take responsibility for its contents.

\section{Ethics approval and consent to participate}

This study used commercially available de-identified secondary data sources and was considered exempt from the requirements for "human subjects' research" in the United States as it does not contain 18 elements of private health information (PHI).

(HIPAA Privacy Rule: https://privacyruleandresearch.nih.gov/pr_08.asp).

\section{Competing interests}

The study was funded by Pfizer, Inc. Pfizer markets a pneumococcal vaccine in the United States. JH, RC, and RS are employees and stock holders of Pfizer, Inc. JB received an unrelated educational grant from Pfizer, Inc. during 2014-16.

\section{Publisher's Note}

Springer Nature remains neutral with regard to jurisdictional claims in published maps and institutional affiliations.

\section{Author details}

'Department of Pharmaceutical Outcomes \& Policy, University of Florida College of Pharmacy, Gainesville, USA. ${ }^{2}$ Global Health and Value, Real World Data and Analytics, Pfizer Inc., New York, NY, USA. ${ }^{3}$ Global Product Development, Statistical Research Data Center, Pfizer, Inc., Collegeville, PA, USA. ${ }^{4}$ Global Health and Value, Outcomes and Evidence, Pfizer, Inc., Collegeville, PA, USA.

\section{Received: 27 December 2017 Accepted: 11 April 2018}

\section{Published online: 16 April 2018}

\section{References}

1. Yu H, Rubin J, Dunning S, Li S, Sato R. Clinical and economic burden of community-acquired pneumonia in the Medicare fee-for-service population. J Am Geriatr Soc. 2012;60(11):2137-43.

2. Average length of stay for discharges from short-stay hospitals, by age and first-listed diagnosis [http://www.cdc.gov/nchs/data/nhds/2average/ 2010ave2_dischargesage.pdf]. Accessed 15 Nov 2017.

3. Jackson ML, Neuzil KM, Thompson WW, Shay DK, Yu O, Hanson CA, Jackson $L A$. The burden of community-acquired pneumonia in seniors: results of a population-based study. Clinical infectious diseases : an official publication of the Infectious Diseases Society of America. 2004;39(11):1642-50.

4. Wroe PC, Finkelstein JA, Ray GT, Linder JA, Johnson KM, Rifas-Shiman S, Moore MR, Huang SS. Aging population and future burden of pneumococcal pneumonia in the United States. J Infect Dis. 2012;205(10):1589-92.

5. Niederman MS. In the clinic: community-acquired pneumonia. Ann Intern Med. 2015;163(7):ITC1-17.

6. Jackson ML, Nelson JC, Jackson LA. Risk factors for community-acquired pneumonia in immunocompetent seniors. J Am Geriatr Soc. 2009;57(5):882-8.

7. Centers for Disease Control and P. Use of 13-valent pneumococcal conjugate vaccine and 23-valent pneumococcal polysaccharide vaccine for adults with immunocompromising conditions: recommendations of the advisory committee on immunization practices (ACIP). MMWRMorbidity and mortality weekly report. 2012;61(40):816-9.

8. Number of discharges from short-stay hospitals, by first-listed diagnosis and age: United States 2010. [http://www.cdc.gov/nchs/data/nhds/3firstlisted/ 2010first3_numberage.pdf]. Accessed 15 Nov 2017.
9. Singer A, Exuzides A, Spangler L, O'Malley C, Colby C, Johnston K, Agodoa I, Baker J, Kagan R. Burden of illness for osteoporotic fractures compared with other serious diseases among postmenopausal women in the United States. Mayo Clin Proc. 2015;90(1):53-62.

10. Gorelick PB, Farooq MU. Min J: population-based approaches for reducing stroke risk. Expert Rev Cardiovasc Ther. 2015;13(1):49-56.

11. Medicare Advantage 2017 Spotlight: Enrollment Market Update [https:// www.kff.org/medicare/issue-brief/medicare-advantage-2017-spotlightenrollment-market-update/]. Accessed 17 Nov 2017.

12. Veselovskiy G. Medicare advantage demographics report. In: America's health insurance plans center for policy and research; 2015.

13. Deyo RA, Cherkin DC, Ciol MA. Adapting a clinical comorbidity index for use with ICD-9-CM administrative databases. J Clin Epidemiol. 1992;45(6):613-9.

14. Quan H, Sundararajan V, Halfon P, Fong A, Burnand B, Luthi JC, Saunders LD, Beck CA, Feasby TE, Ghali WA. Coding algorithms for defining comorbidities in ICD-9-CM and ICD-10 administrative data. Med Care. 2005;43(11):1130-9.

15. Centers for Medicare and Medicaid Services TJC: Pneumonia: hospital 30day, all-cause, risk-standardized mortality rate (RSMR) following pneumonia hospitalization. In.; 2014

16. Mandell LA, Wunderink RG, Anzueto A, Bartlett JG, Campbell GD, Dean NC, Dowell SF, File TM Jr, Musher DM, Niederman MS, et al. Infectious Diseases Society of America/American Thoracic Society consensus guidelines on the management of community-acquired pneumonia in adults. Clinical infectious diseases : an official publication of the Infectious Diseases Society of America. 2007;44(Suppl 2):S27-72.

17. Tomczyk S, Bennett NM, Stoecker C, Gierke R, Moore MR, Whitney CG, Hadler S, Pilishvili T, Centers for Disease Control and P. Use of 13-valent pneumococcal conjugate vaccine and 23-valent pneumococcal polysaccharide vaccine among adults aged $>/=65$ years: recommendations of the advisory committee on immunization practices (ACIP). MMWRMorbidity and mortality weekly report. 2014;63(37):822-5.

18. Jain S, Self WH, Wunderink RG, Fakhran S, Balk R, Bramley AM, Reed C, Grijalva CG, Anderson EJ, Courtney DM, et al. Community-acquired pneumonia requiring hospitalization among U.S. adults. N Engl J Med. 2015;373(5):415-27.

19. Baxter R, Ray GT, Fireman BH. Effect of influenza vaccination on hospitalizations in persons aged 50 years and older. Vaccine. 2010;28(45):7267-72.

20. Bonten MJ, Huijts SM, Bolkenbaas M, Webber C, Patterson S, Gault S, van Werkhoven $\mathrm{CH}$, van Deursen AM, Sanders EA, Verheij TJ, et al. Polysaccharide conjugate vaccine against pneumococcal pneumonia in adults. N Engl J Med. 2015;372(12):1114-25.

21. Ochoa-Gondar O, Vila-Corcoles A, Rodriguez-Blanco T, Gomez-Bertomeu F, Figuerola-Massana E, Raga-Luria X, Hospital-Guardiola I. Effectiveness of the 23-valent pneumococcal polysaccharide vaccine against communityacquired pneumonia in the general population aged $>/=60$ years: 3 years of follow-up in the CAPAMIS study. Clinical infectious diseases : an official publication of the Infectious Diseases Society of America. 2014;58(7):909-17.

22. Jackson LA, Neuzil KM, Yu O, Benson P, Barlow WE, Adams AL, Hanson CA, Mahoney LD, Shay DK, Thompson WW. Effectiveness of pneumococcal polysaccharide vaccine in older adults. N Engl J Med. 2003;348(18):1747-55.

23. Grijalva CG, Zhu Y, Williams DJ, Self WH, Ampofo K, Pavia AT, Stockman CR, McCullers J, et al. Association between hospitalization with communityacquired laboratory-confirmed influenza pneumonia and prior receipt of influenza vaccination. JAMA. 2015:1488-97.

24. Williams WW, Lu PJ, O'Halloran A, Bridges CB, Kim DK, Pilishvili T, Hales CM, Markowitz LE, Centers for Disease Control and P. Vaccination coverage among adults, excluding influenza vaccination - United States, 2013. MMWRMorbidity and mortality weekly report. 2015;64(4):95-102.

25. Lu PJ, Nuorti JP. Pneumococcal polysaccharide vaccination among adults aged 65 years and older, U.S., 1989-2008. American Journal of Preventive Medicine. 2010;39(4):287-95.

26. Healthy people 2020 topics \& objectives: Immunization and infectious diseases [http://www.healthypeople.gov/2020/topics-objectives/topic/ immunization-and-infectious-diseases/objectives]. Accessed 15 Nov 2017.

27. Black CL, Williams WW, Warnock R, Pilishvili T, Kim D, Kelman JA. Pneumococcal vaccination among Medicare beneficiaries occurring after the advisory committee on immunization practices recommendation for routine use of 13-valent pneumococcal conjugate vaccine and 23 -valent pneumococcal polysaccharide vaccine for adults aged $\geq 65$ years. MMWR Morb Mortal Wkly Rep. 2017;66(27):728-33.

28. Smith KJ, Wateska AR, Nowalk MP, Raymund M, Nuorti JP, Zimmerman RK Cost-effectiveness of adult vaccination strategies using pneumococcal 
conjugate vaccine compared with pneumococcal polysaccharide vaccine. JAMA. 2012;307(8):804-12.

29. Maciosek MV, Coffield AB, Edwards NM, Flottemesch TJ, Goodman MJ, Solberg LI. Priorities among effective clinical preventive services: results of a systematic review and analysis. Am J Prev Med. 2006;31(1):52-61.

30. Smith KJ, Wateska AR, Nowalk MP, Raymund M, Lee BY, Zimmerman RK. Modeling of cost effectiveness of pneumococcal conjugate vaccination strategies in U.S. older adults. Am J Prev Med. 2013;44(4):373-81.

31. Stoecker C, Kim L, Gierke R, Pilishvili T. Incremental cost-effectiveness of 13valent pneumococcal conjugate vaccine for adults age 50 years and older in the United States. J Gen Intern Med. 2016;31(8):901-8.

32. Lau D, Hu J, Majumdar SR, Storie DA, Rees SE, Johnson JA. Interventions to improve influenza and pneumococcal vaccination rates among communitydwelling adults: a systematic review and meta-analysis. Ann Fam Med. 2012; 10(6):538-46.

33. Zimmerman RK, Santibanez TA, Fine MJ, Janosky JE, Nowalk MP, Bardella IJ, Raymund M, Wilson SA. Barriers and facilitators of pneumococcal vaccination among the elderly. Vaccine. 2003;21(13-14):1510-7.

34. Department of Health and Human Services (HHS). The affordable care act and immunization. http://www.hhs.gov/healthcare/facts-and-features/factsheets/aca-and-immunization/index.html. Accessed 17 Nov 2015.

35. Goad JA, Taitel MS, Fensterheim LE, Cannon AE. Vaccinations administered during off-clinic hours at a national community pharmacy: implications for increasing patient access and convenience. Ann Fam Med. 2013;11(5):429-36.

36. American Pharmacists Association. Pharmacist administered vaccines. http:// www.pharmacist.com/sites/default/files/PharmacistlZAuthority.pdf. Accessed 17 Nov 2015.

37. Centers for Medicare and Medicaid Services. Your Medicare coverage: Pneumococcal shots. https://www.medicare.gov/coverage/pneumococcalshots.html. Accessed 17 Oct 2017.

38. Winston CA, Wortley PM, Lees KA. Factors associated with vaccination of medicare beneficiaries in five U.S. communities: results from the racial and ethnic adult disparities in immunization initiative survey, 2003. J Am Geriatr Soc. 2006;54(2):303-10

39. Nichol KL, Mac Donald R, Hauge M. Factors associated with influenza and pneumococcal vaccination behavior among high-risk adults. J Gen Intern Med. 1996:11(11):673-7.

40. Ehresmann KR, Ramesh A, Como-Sabetti K, Peterson DC, Whitney CG, Moore KA. Factors associated with self-reported pneumococcal immunization among adults 65 years of age or older in the Minneapolis-St. Paul metropolitan area. Prev Med. 2001;32(5):409-15.

41. Pilishvili T, Lexau C, Farley MM, Hadler J, Harrison LH, Bennett NM, Reingold A, Thomas A, Schaffner W, Craig AS, et al. Sustained reductions in invasive pneumococcal disease in the era of conjugate vaccine. J Infect Dis. 2010;201(1):32-41.

42. National Committee for Quality Assurance. HEDIS 2015. http://uww.ncqa.org/ HEDISQualityMeasurement/HEDISMeasures/HEDIS2015.aspx. Accessed 17 Oct 2017.

43. Centers for Medicare and Mediciad Services. Physician quality reporting system. https://www.cms.gov/Medicare/Quality-lnitiatives-Patient-AssessmentInstruments/PQRS/index.html?redirect=/pqri/. Accessed 17 Oct 2017.

44. Gavrielov-Yusim N, Friger M. Use of administrative medical databases in population-based research. J Epidemiol Community Health. 2014;68(3):283-7.

45. lezzoni LI. Assessing quality using administrative data. Ann Intern Med. 1997;127(8 Pt 2):666-74.

46. Schneeweiss $\mathrm{S}$, Avorn J. A review of uses of health care utilization databases for epidemiologic research on therapeutics. J Clin Epidemiol. 2005;58(4): 323-37.

47. Pauly NJ, Talbert JC, Brown J. Low-cost generic program use by Medicare beneficiaries: implications for medication exposure misclassification in administrative claims data. J Manag Care Spec Pharm. 2016;22(6):741-51.

Ready to submit your research? Choose BMC and benefit from:

- fast, convenient online submission

- thorough peer review by experienced researchers in your field

- rapid publication on acceptance

- support for research data, including large and complex data types

- gold Open Access which fosters wider collaboration and increased citations

- maximum visibility for your research: over $100 \mathrm{M}$ website views per year

At BMC, research is always in progress.

Learn more biomedcentral.com/submissions 